\title{
Spectrophotometric analysis evaluating apical microleakage in retrograde filling using GIC, MTA and biodentine: an in-vitro study
}

Manisha Nepal ${ }^{1 *}$ D, Snigdha Shubham ${ }^{1}$, Rupam Tripathi ${ }^{1}$, Jwolan Khadka², Deepa Kunwar ${ }^{3}$, Vanita Gautam ${ }^{1}$ and Narayan Gautam ${ }^{4}$

\begin{abstract}
Background: The present study compares the apical microleakage of three different root-end filling materials in which the retrograde cavity is prepared by two different burs.

Methods: Eighty extracted single rooted maxillary and mandibular premolars were taken. Root canal treatment was completed. Apical $3 \mathrm{~mm}$ of all the teeth were resected with diamond disk. The tooth were divided into four groups with two subgroups for each group containing 10 tooth $(N=10)$ as: Group IA (Negative Control and IB (Positive Control); Group IIA and IIB: Prepared with round carbide bur and round diamond bur respectively, filled with GIC; Group IIIA and IIIB: Prepared with round carbide bur and round diamond bur respectively, filled with MTA; Group IVA and IVB: Prepared with round carbide bur and round diamond bur, filled with Biodentine. After applying two coats of nail varnish leaving apical $3 \mathrm{~mm}$ (except for negative control group) all teeth were immersed in 2\% methylene blue for 3 days and again in $65 \%$ nitric acid for next 3 days for extraction of dye. The obtained solution was then transferred to eppendorf tube and centrifuged in microcentrifuges at 14,000 revolution per minutes (RPM) for $5 \mathrm{~min}$. Optical density or absorbance of the supernatant solution was measured with UV spectrophotometer at $550 \mathrm{~nm}$

Results: The absorbance of the supernatant solution after dye extraction is decreasing in the order of positive control> GIC > MTA > Biodentine> negative control group. The significant difference was observed between GIC and MTA $(p=0.0001)$ and GIC and Biodentine $(p=0.0001)$ with two different burs but statistically non-significant difference was observed between MTA and Biodentine with Carbide bur $(p=0.127)$ and Diamond bur $(p=0.496)$ respectively.

Conclusions: Within the limitations of the present study, it can be concluded that Biodentine and MTA showed less microleakage as compared to GIC. There is no significant difference between mean microleakage of MTA and Biodentine. However, the mean OD of the Biodentine was least of all evaluated materials. Preparation of the rootend using round carbide bur as well as round diamond burs showed comparable microleakage for all three filling materials.
\end{abstract}

Keywords: Apical microleakage, Apicoectomy, Biodentine, GIC, MTA, Root-end filling materials

\footnotetext{
* Correspondence: manisha.nepal.mn@gmail.com

${ }^{1}$ Department of Conservative Dentistry and Endodontics, Universal College of

Medical Sciences, Bhairahawa, Nepal

Full list of author information is available at the end of the article
}

(c) The Author(s). 2020 Open Access This article is distributed under the terms of the Creative Commons Attribution 4.0 International License (http://creativecommons.org/licenses/by/4.0/), which permits unrestricted use, distribution, and reproduction in any medium, provided you give appropriate credit to the original author(s) and the source, provide a link to the Creative Commons license, and indicate if changes were made. The Creative Commons Public Domain Dedication waiver (http://creativecommons.org/publicdomain/zero/1.0/) applies to the data made available in this article, unless otherwise stated. 


\section{Background}

Conventional Root Canal Treatment (RCT) is the highly predictable treatment option with the aim of elimination and future exclusion of all the microorganisms from the root canal system [1]. The most important factor to achieve this is complete removal of infected canal contents followed by obliteration of the root canal system and development of fluid tight seal. Nonsurgical endodontic treatment is a predictable and reliable treatment with high success rates ranging from 86 to $98 \%$ [2]. In some cases, despite meticulous canal cleaning, shaping, disinfection, and obturation, endodontic treatment might still fail. This unsuccessful result may related to bacterial persistence in the apical canal in areas unaffected by treatment procedures [3]. Procedural errors during instrumentation like ledges, perforations and instrument breakage, canal calcifications and anatomic anomalies can negatively affect the efficient performance of cleaning and shaping of the root canal system and lead to treatment failure $[4,5]$.

Nonsurgical retreatment is the preferred treatment option if conventional endodontic treatment is unsuccessful. According to Bergenholtz et al. [6] this treatment usually results in successful outcomes. However, ideal goals may be difficult to achieve with a retreatment approach because of the complexity of root canal systems, inadequate instrumentation and presence of physical barriers viz. a viz. anatomical, post and core restoration, separated instruments, etc. Hence, in such cases surgical endodontic therapy becomes the first alternative to save the involved tooth.

The teeth committed with persistent periapical lesion in which root canal retreatment had failed or is not feasible is salvaged by apicoectomy which is a wellestablished surgical procedure. Saving the naturals is our prime concern so this procedure is an alternative to avoid extractions. It is an important conservative treatment and an extension of endodontic therapy whose purpose is to preserve the tooth [7].

Apicoectomy procedure includes exposure of the involved root apex, curettage of the lesion,root-end resection, root-end cavity preparation and root-end filling. The concern of apicoectomy is not just only the removal of the diseased periapical tissue and apex of root, but also, resealing the root canal system with a suitable rootend filling material.

Gutta Percha, Amalgam, Cavit, Intermediate Restorative Material, Super EBA, Diaket, GlassIonomer Cements, Composite Resins, Carboxylate Cements, Zinc Phosphate Cements, Zinc Oxide Eugenol Cements etc. had been used traditionally as a root end filling material [8]. In 1993, MTA was developed as a new root-end filling material at Loma Linda University, California, USA. It is regarded as an ideal root-end filling material and has become the gold standard against which the newer materials are compared [9]. Other newer bioceramic materials like BioAggregate, Biodentine, Endosequence root repair material (ERRM), iRoot BP Plus, etc. have been marketed recently.

Apical microleakage is the leakage along the interface between the filling material and the canal wall [10]. Apical leakage continues to be a topic of interest because in spite of advances in endodontics, clinical failure still occurs. The purpose of root-end filling material is to entomb surviving microbes in the root canal space so that they cannot multiply and/or communicate with the periradicular tissues, also to prevent influx of periapical fluids which nourish surviving microbes in the root canal [11]. Inappropriate marginal sealing of retrocavity may allow percolation of microorganisms and their products between the root canal system and periradicular tissues, thus leading to treatment failure.

The quality of apical seal achieved by root-end filling materials has been assessed by various means like the degree of dye penetration, dye extraction, radioisotope penetration, bacterial penetration, electro-chemical means and fluid filtration techniques. Dye extraction method employs the immersion of samples in dye followed by acid that liberates all of the dye from within the interface, and the optical density of the solution is recorded by the use of a spectrophotometer. Thus, it is possible to quantitatively measure how much dye penetrates through the margins of restoration [12].

Since the adequacy of the "apical seal" is considered paramount to the success of apicectomies, the sealing ability of a new material must be evaluated [1]. Therefore, this study is aimed to evaluate the apical sealing ability of GIC, MTA and Biodentine as a root-end filling material by preparing retrograde cavity with two different burs: round carbide bur and round diamond bur by utilizing dye extraction method for leakage assessment.

\section{Methods}

The study was conducted in Department of Conservative dentistry and Endodontics from March 2017 to August 2017 with due approval of Institutional Review Committee (UCMS/IRC/092) of Universal College of Medical Sciences, Bhairahawa, Nepal. The consent of the participant for the use of extracted tooth is not necessary according to the Institutional Review Committee which comes under National regulation (Nepal). Eighty intact human maxillary and mandibular premolars with single root and canal extracted for orthodontic purpose from the patients of the similar age group, caries free, similar dimensions, without signs of fractures/cracks and with similar tooth length were selected as a sample. Teeth were immersed in 5\% sodium hypochlorite solution for $5 \mathrm{~min}$ and ultrasonic scaler was used to remove soft 
tissues, calculus and any external debris from the teeth, then stored in a container containing 10\% buffered formalin solution until further use.

Access opening was done with Endo Access burs (Dentsply) and working length determined with \#15 K file (Diadent), confirmed by Radiovisiograph (RVG). Chemomechanical preparation was done using hand $\mathrm{K}$ files (\#40,2\% taper) with step-back technique, irrigation done with 5\% NaOCl (Pyrax, India), 17\% EDTA (Ammdent) and normal saline. Canal was dried with paper points and obturation done with gutta percha (Diadent) and zinc oxide eugenol sealer using lateral condensation technique with finger spreader. A final radiograph was taken using RVG that demonstrated adequately the obturation of each canal. Access cavity was restored with Cavit. Samples were stored in 100\% relative humidity for $24 \mathrm{~h}$. Apical $3 \mathrm{~mm}$ of all the teeth were resected at $90^{\circ}$ angle axis to the long axis of the root with diamond disk mounted in straight handpiece of micromotor. Samples were divided into four groups with two subgroups of 10 sample each $(N=10)$ as:

Group I: Control Group.

Group IA (Negative Control): without root-end preparation and without root-end filling; all surface covered with nail varnish.

Group IB (Positive Control): without root- end preparation and without root-end filling.

Group II: Root-end filling with GIC, where retrograde cavity is prepared with.

Group IIA: round carbide bur.

Group IIB: round diamond bur.

Group III: Root-end filling with MTA, where retro-

grade cavity is prepared with

Group IIIA: round carbide bur.

Group IIIB: round diamond bur.

Group IV: Root-end filling with Biodentine where

retrograde cavity is prepared with.

Group IVA: round carbide bur.

Group IVB: round diamond bur.

Retrograde preparations were made in all the teeth uniformly to a depth of $3 \mathrm{~mm}$ using two different burs: round carbide bur and round diamond bur (SS White). Root-end cavity was irrigated with normal saline, dried with absorbent paper points and restored with GIC (Shofu, Japan), MTA (MTA Angelus ${ }^{\mathrm{R}}$, Brazil) and Biodentine $^{\text {ra }}$ (Septodont, France) in the respective groups. Samples were coated with two coats of nail varnish leaving apical $3 \mathrm{~mm}$ (except Group IA where all surface was covered with nail varnish). After the varnish was dried, samples were immersed in $5 \mathrm{ml}$ of $2 \%$ methylene blue in 80 different air tight container and stored in incubator at $37^{\circ} \mathrm{C}$ for $72 \mathrm{~h}$. Samples were washed under running tap water to remove the traces of the dye, dried and nail varnish removed with scalpel. Each sample were immersed and stored in test tube containing $1 \mathrm{ml}$ of freshly prepared $65 \% \mathrm{HNO}_{3}$ for $72 \mathrm{~h}$. The obtained solution was transferred to effendorf tubes and centrifuged at 14,000 RPM for $5 \mathrm{~min}$ to separate GP debris from the extracted dye. Dye concentration in the supernatant solution was analyzed using an UV spectrophotometer at $550 \mathrm{~nm}$ taking concentrated nitric acid as a blank.

Statistical analysis was performed using Statistical Package for the Social Sciences (SPSS) version 20.00 (SPSS Inc., Chicago IL) to compare the mean apical microleakage of the groups and determine the significance of differences between different groups. Quantitative statistical analysis was done for the parameters. Mean and standard deviation was calculated for all scores obtained from 8 different study subgroups of four groups. One way ANOVA followed by post hoc Tukey HSD was used to analyse to compare mean \pm SD. $p<$ 0.05 was considered to be statistically significant.

\section{Result}

Quantitative statistical analysis was done for the parameters. Mean and standard deviation was calculated for all scores obtained from 8 different study subgroups of four groups viz. a viz. (I) Control Group (Negative, Positive), (II) GIC Group (Carbide, Diamond), (III) MTA (Carbide, Diamond), (IV) Biodentine (Carbide, Diamond). Comparison of microleakage among 8 subgroups based on Optical Density (OD) showed least microleakage in Biodentine group prepared by carbide bur as depicted in Table 1 and Fig. 1.

One way ANOVA followed by post hoc Tukey HSD was used to analyse to compare mean \pm SD between the groups with positive and negative controls which also showed Biodentine to have least microleakage in comparison to negative control as shown by Table 2 .

Table 1 Comparison of microleakage among 8 subgroups based on Optical Density (OD)

\begin{tabular}{llll}
\hline Groups & Mean & S.D & N \\
\hline Group IA & 0.130 & 0.029 & 10 \\
Group IB & 0.948 & 0.287 & 10 \\
Group IIA & 0.550 & 0.060 & 10 \\
Group IIB & 0.557 & 0.095 & 10 \\
Group IIIA & 0.278 & 0.042 & 10 \\
Group IIIB & 0.254 & 0.055 & 10 \\
Group IVA & 0.139 & 0.033 & 10 \\
Group IVB & 0.153 & 0.038 & 10 \\
Total & 0.376 & 0.292 & 80 \\
\hline
\end{tabular}

Shows the mean \pm S.D. OD for different subgroups to assess microleakage 


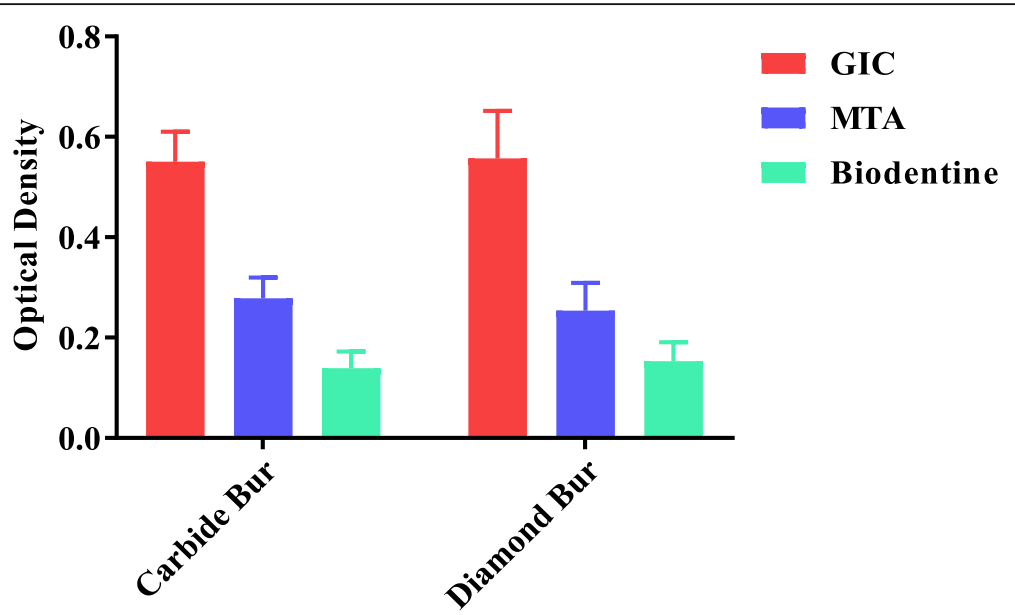

\section{Retrograde cavity}

Fig. 1 Comparison of (Mean \pm S.D) Optical Density of three different root-end filling materials by two different burs. Graph 1 depicts mean \pm S.D. OD for samples filled with GIC, MTA and Biodentine in which retrograde cavity was prepared with two different round burs: Carbide versus Diamond respectively. The significant difference was observed in between GIC and MTA ( $p=0.0001)$ as well as GIC and Biodentine $(p=0.0001)$ with two different burs but statistically non-significant difference was observed between MTA and Biodentine with Carbide bur ( $p=0.127)$ and Diamond bur $(p=0.496)$ respectively. While comparing Mean \pm S.D. for two different round burs for retrograde cavity preparations (Carbide versus Diamond) of three different materials, statistically non-significant difference was observed between intra-groups GIC-Carbide versus GIC-Diamond $(p=1.000)$, MTA-Carbide versus MTA-Diamond $(p=1.000)$ and Biodentine-Carbide versus Biodentine-Diamond $(p=1.000)$.

\section{Discussion}

Endodontic surgery may become the last resort for salvaging the affected tooth, if conventional endodontic treatment fails and retreatment is neither indicated nor feasible. Removal of the infected root-end and sealing any remaining bacteria in the root canal system from the periradicular tissues is the goal of surgical intervention [13]. The surgical procedure includes three critical steps to eliminate persistent endodontic pathogens: 1 ) surgical debridement of pathological periradicular tissue, 2) rootend resection (apicoectomy), and 3) retrograde root canal obturation (root-end filling).

Kim S and Kratchman S suggested removing at least 3 $\mathrm{mm}$ of the root-end which reduces $98 \%$ of the apical ramifications and $93 \%$ of the lateral canals [14]. They also proposed that root-end amputation of less than 3 $\mathrm{mm}$ does not remove all of the lateral canals and apical ramifications which poses a risk of reinfection and eventual failure. Apart from amount, the plane of sectioning is to be considered equally during root resection. Ideally, the short bevel $\left(0^{\circ}\right)$ that is as perpendicular to the long axis of the tooth as possible conserves the root length and exposes less dentinal tubules thereby opening less tubules to be exposed to the environment, which allows less microleakage over a period of time [15].

Taschieri $\mathrm{S}$ et al. investigated the quality of root-end filling in cases of periapical lesions persisting after endodontic surgery. Failure of apicoectomy was because of an imperfect seal at the interface between the root-end filling and the cavity margin. The presence of such a gap

Table 2 Comparative analysis of microleakage with negative control and positive control

\begin{tabular}{|c|c|c|c|c|c|}
\hline Groups & Mean $(\mathrm{OD}) \pm S . D$ & Negative Control Mean $(\mathrm{OD}) \pm$ S.D & $P$-value & Positive Control Mean (OD) \pm S.D & $P$-value \\
\hline Group IIA & $0.550 \pm 0.060$ & & 0.0001 & & 0.0001 \\
\hline Group IIB & $0.557 \pm 0.095$ & & 0.0001 & & 0.0001 \\
\hline Group IIIA & $0.278 \pm 0.042$ & & 0.084 & & 0.0001 \\
\hline Group IIIB & $0.254 \pm 0.055$ & $0.130 \pm 0.029$ & 0.234 & $0.948 \pm 0.287$ & 0.0001 \\
\hline Group IVA & $0.139 \pm 0.033$ & & 1.000 & & 0.0001 \\
\hline Group IVB & $0.153 \pm 0.036$ & & 1.000 & & 0.0001 \\
\hline
\end{tabular}

Illustrates the comparison of mean \pm S.D. of OD for samples filled with GIC, MTA and Biodentine in which retrograde cavity was prepared by two different round burs: Carbide versus Diamond with that of negative and positive control group. The significant difference was observed between GIC and negative control $(p=$ $0.0001)$ and GIC and positive control $(p=0.0001)$. The non-significant difference was observed between MTA and negative control $(p=0.084 / C a r b i d e, p=0.234 /$ Diamond) and the significant difference between MTA and positive control $(p=0.0001)$. Moreover, the non-significant difference was observed between Biodentine and negative control with both burs $(p=1.000)$ and significant difference observed between Biodentine and positive control $(p=0.0001)$ respectively. 
would favour a continuous bacterial leakage from the infected root canal system to the periapical tissue thereby sustaining inflammation [16]. According to Cohen, the ideal root-end filling material should seal the contents of the root canal system within the canal, prevent egress of any bacteria, bacterial by-products, or toxic material into the surrounding periradicular tissues [17]. Various studies have emphasized the importance of root-end fillings in outcomes of apicoectomies by reporting that teeth with root-end fillings showed favorable results compared with those without root-end fillings [18-20]. Therefore, sealing the root apex with a proper root-end filling material is crucial.

Various experiments can be carried out to evaluate the microleakage like dye extraction, dye penetration, radioisotope, bacterial penetration, fluid filtration etc. The dye penetration method used for measuring sealing ability is the popular and most widely used but this technique suffers from severe limitations. This technique relies on randomly cutting the root into two pieces, without knowing if the section goes through the deepest dye penetration so it under evaluates the dye penetration and gives randomly chosen results [12]. Apart from that, the measurement of leakage is qualitative too. Whereas, in dye extraction method, all the dye that leaked through the apex is recovered by dissolving in acid which avoids the limitations of sectioning the root and it also quantitatively measures the optical density of the solution by the use of a spectrophotometer thus provides reliable results in microleakage studies [21]. However, sample storage in $10 \%$ formalin may introduce a significant source of experimental variability influencing leakage results as compared to freshly extracted teeth [22].

In the present study, the mean \pm S.D. OD for GICCarbide as compared to MTA-Carbide and BiodentineCarbide was found to be statistically significant difference $(p=0.0001)$. Similarly, the mean \pm S.D. OD for GIC-Diamond as compared to MTA-Diamond and Biodentine-Diamond was also statistically significant difference $(p=0.0001)$. This result shows that the microleakage occurs more in one material as compared to others. However, while comparing GIC with negative control, it shows the significant difference in the microleakage butcomparing MTA and Biodentine with negative control it shows statistically non-significant difference representing that MTA and Biodentine have better apical seal as compared to GIC.

Moreover, in the present study the mean \pm S.D. OD for MTA-Carbide $(0.278 \pm 0.042)$ and BiodentineCarbide $(0.139 \pm 0.033)$ was statistically non-significant difference $(p=0.127)$. Similarly, the mean \pm S.D. OD for MTA-Diamond $(0.254 \pm 0.055)$ and Biodentine-Diamond $(0.153 \pm 0.038)$ was also statistically non-significant difference $(p=0.496)$ showing the comparability of both materials in providing apical seal. In the same way, mean \pm S.D. OD of MTA-Carbide and MTA-Diamond with were statistically non-significant difference as compared to negative control $(p=0.084$ and $p=0.234)$ respectively. Likewise, mean \pm S.D. OD of BiodentineCarbide and Biodentine-Diamond were also statistically non-significant difference as compared to negative control $(p=1.000)$. Hence, MTA and Biodentine had similar apical sealing ability as observed by its optical density near to negative control which was statistically nonsignificant. Apart from that, the mean \pm S.D. OD of Biodentine was lower than that of MTA representing Biodentine is the best material for preventing apical microleakage.

Mineral Trioxide Aggregate has been proven to show less microleakage compared to other materials [5]. However, in this study the least microleakage was exhibited by Biodentine although the difference was not statistically significant. The result of our study is in concurrence with the study conducted by Khandelwal $\mathrm{A}$ et al. [23], Radeva E et al. [24], Naik MM et al. [25], Kokate SR et al. [8] Comparing the sealing ability of MTA and Biodentine as root-end filling material Khandelwal A et al. [23] concluded that Biodentine can be used as a replacement for MTA. The study by Radeva E et al. [24] concluded that Biodentine can be more effective as apical sealing material compared to MTA. Naik $\mathrm{MM}^{25}$ concluded that the apical seal obtained with Biodentine was superior to that obtained with MTA.

Similarly, Kokate SR et al. [8] compared the microleakage of MTA, GIC \& Biodentine using dye penetration method under stereomicroscope. The results of their study showed that there was significantly less leakage in Biodentine when compared to MTA \& GIC. This result is in agreement with the present study. However, the study conducted by Mandava P et al. [26] evaluated the apical microleakage of root-end cavities filled with MTA, Biodentine and LC GIC using two different cavity preparation techniques that is conventional bur preparation and ultrasonic tip preparation. The result of their study showed significantly less microleakage of MTA compared to Biodentine and LC GIC, which is in contrast to our study.

In the current study, two different burs were used for preparing retrograde cavity. The rationale behind using two different burs is to determine the effect of smear layer on microleakage. Surgical smear layer in endodontics is defined as a smear layer, which contains microorganisms and necrotic pulpal tissues which is formed on the dentinal surfaces, cut by the instruments during apicoectomy and retrograde cavity preparation [25]. Citric acid, EDTA, 35\% orthophosphoric acid and BioPure $\mathrm{MTAD}^{\mathrm{im}}$ (mixture of tetracycline isomer, acid and detergent) have been recommended for the removal of 
surgical smear layer but in our study no attempt was done to remove it as the retrograde cavity was just irrigated with normal saline. The thickness of the smear layer is also affected by type of the bur used. Several studies have demonstrated that carbide bur produces thinner smear layer compared to that of diamond bur [27-29]. However, the current study showed the mean \pm S.D. OD of GIC-Carbide and GIC-Diamond, MTACarbide and MTA-Diamond and Biodentine-Carbide and Biodentine-Diamond respectively with statistically non-significant difference $(p=1.000)$. Hence, in this study, the comparable nature of two different retrograde preparations were observed and can be used according to ease.

As in vitro evaluation does not always reveal their in vivo performance, hence clinical testing are still required for higher impact of result.

\section{Conclusion}

Biodentine and MTA showed less microleakage as compared to GIC. There is no significant difference between mean microleakage of MTA and Biodentine. However, the mean OD of the biodentine was least of all evaluated materials. Root end preparation either by round carbide bur or round diamond bur didn't show any variation in microleakage.

\section{Abbreviations}

ANOVA: Analysis of Variance; EDTA: Ethylene Diamine Tetraacetic Acid; GIC: Glass lonomer Cement; GP: Gutta Percha; MTA: Mineral Trioxide Aggregate; OD: Optical Density; RCT: Root Canal Treatment; RPM: Revolutions per minute; SD: Standard Deviation; UV: Ultraviolet

\section{Acknowledgements}

We would like to thank chairperson and staffs for general support of using UV spectrophotometer at the Department of Pharmacology and microcentrifuges at the Department of Microbiology, Universal College of Medical Sciences.

\section{Authors' contributions}

$\mathrm{NM}, \mathrm{KJ}$ and GN performed laboratory experiments. SS and GN analyzed the data and evaluated the result. NM and SS wrote the manuscript.TR, KD and GV reviewed the manuscript and proof reading. All the authors read and approved the manuscript.

\section{Funding}

The study was not funded by any organization or company.

\section{Availability of data and materials}

The datasets used and analyzed during the study are available from the corresponding author on reasonable request.

\section{Ethics approval and consent to participate}

This study was conducted after approval of the Institutional Review Committee of Universal College of Medical Sciences (UCMS/RC/092). The consent of the participant for the use of extracted tooth is not necessary according to the Institutional Review Committee which comes under National regulation (Nepal).

\section{Consent for publication}

Not applicable.

\section{Competing interests}

The authors declare that they have no competing interests.

\section{Author details}

${ }^{1}$ Department of Conservative Dentistry and Endodontics, Universal College of Medical Sciences, Bhairahawa, Nepal. ${ }^{2}$ Department of Conservative Dentistry and Endodontics, KIST Medical College, Lalitpur, Nepal. ${ }^{3}$ Department of Conservative Dentistry and Endodontics, Gandaki Medical College, Pokhara, Nepal. ${ }^{4}$ Department of Biochemistry, Universal College of Medical Sciences, Bhairahawa, Nepal.

Received: 7 September 2019 Accepted: 28 January 2020

Published online: 03 February 2020

\section{References}

1. Chong BS, Pitt Ford TR, Watson TF, Wilson RF. Sealing ability of potential retrograde root filling materials. Endod Dent Traumatol. 1995;11(6):264-9.

2. Song $\mathrm{M}$, Kim HC, Lee W, Kim E. Analysis of the cause of failure in nonsurgical endodontic treatment by microscopic inspection during endodontic microsurgery. J Endod. 2011;37:1516-9.

3. Ricucci D, Siqueira JF Jr. Anatomic and microbiologic challenges to achieving success with endodontic treatment: a case report. J Endod. 2008; 34:1249-54

4. Winik R, Araki ÂT, Negrão JAA, Bello-Silva MS, Lage-Marques JL. Sealer penetration and marginal permeability after apicoectomy varying retrocavity preparation and retrofilling material. Braz Dent J. 2006;17(4):323-

5. Bernabé PFE, Holland R, Morandi R, Souza VD, Nery MJ, Otoboni Filho JA, et al. Comparative study of MTA and other materials in retrofilling of pulpless dogs' teeth. Braz Dent J. 2005;16(2):149-55.

6. Torabinejad M, Pitt Ford TR. Root end filling materials: a review. Endod Dent Traumatol. 1996;12(4):161-78.

7. Post LK, Lima FG, Xavier CB, Demarco FF, Gerhardt-Oliveira M. Sealing ability of MTA and amalgam in different root-end preparations and resection bevel angles: an in vitro evaluation using marginal dye leakage. Braz Dent J. 2010; 21(5):416-9.

8. Kokate SR, Pawar AM. An in vitro comparative stereomicroscopic evaluation of marginal seal between MTA, glass ionomer cement \& biodentine as root end filling materials using 1\% methylene blue as tracer. Endodontology. 2010;24(7):36-42.

9. Hemasathya B, Mony CMB, Prakash V. Recent Advances In Root End Filling Materials: A Review. Biomed Pharmacol J. 2015;8(October Spl Edition):21924.

10. Gilheany PA, Figdor D, Tyas MJ. Apical dentin permeability and microleakage associated with root end resection and retrograde filling. J Endod. 1994;20(1):22-6.

11. Trope M, Bunes A, Debelian G. Root filling materials and techniques: bioceramics a new hope? Endod Top. 2015;32(1):86-96.

12. Camps J, Pashley D. Reliability of the dye penetration studies. J Endod. 2003; 29(9):592-4.

13. Christiansen R, Kirkevang L-L, Hørsted-Bindslev P, Wenzel A. Randomized clinical trial of root-end resection followed by root-end filling with mineral trioxide aggregate or smoothing of the orthograde gutta-percha root filling - 1-year follow-up. Int Endod J. 2009:42(2):105-14.

14. Kim S, Kratchman S. Modern endodontic surgery concepts and practice: a review. J Endod. 2006;32(7):601-23.

15. Stropko JJ, Doyon GE, Gutmann JL. Root-end management: resection, cavity preparation, and material placement. Endod Top. 2005;11(1):131-51.

16. Taschieri S, Bettach R, Lolato A, Moneghini L, Del Fabbro M. Endodontic surgery failure: SEM analysis of root-end filling. J Oral Sci. 2011;53(3):393-6.

17. Hargreaves KM, Cohen S. Periradicular Surgery. In: Cohen's Pathways of the Pulp. 10th ed. St. Louis, MO: Elsevier; 2011. p. 752.

18. Altonen M, Mattila K. Follow-up study of apicoectomized molars. Int J Oral Surg. 1976;5(1):33-40.

19. Lustmann J, Friedman S, Shaharabany V. Relation of pre- and intraoperative factors to prognosis of posterior apical surgery. J Endod. 1991;17(5):239-41.

20. Rahbaran S, Gilthorpe MS, Harrison SD, et al. Comparison of clinical outcome of periapical surgery in endodontic and oral surgery units of a teaching dental hospital: a retrospective study. Oral Surg Oral Med Oral Pathol Oral Radiol Endod. 2001;91(6):700-9. 
21. Veríssimo DM, do Vale MS. Methodologies for assessment of apical and coronal leakage of endodontic filling materials: a critical review. J Oral Sci. 2006:48:93-8.

22. Salem-Milani A, Zand V, Asghari-Jafarabadi M, Zakeri-Milani P, Banifatemeh A. The effect of protocol for disinfection of extracted teeth recommended by center for disease control (CDC) on microhardness of enamel and dentin. J Clin Exp Dent. 2015;7(5):e552-6.

23. Khandelwal A, Karthik J, Nadig RR, Jain A. Sealing ability of mineral trioxide aggregate and Biodentine as the root end filling material, using two different retro preparation techniques - An in vitro study. Int J Contemp Dent Med Rev. 2015;2015:1-6.

24. Radeva E, Uzunov T, Kosturkov D. Microleakage associated with retrograde filling after root end resection (in vitro study). J IMAB. 2014;20(3):578-83.

25. Naik MM, Ataide I, Fernades M, Lambor R. Assessment of apical seal obtained after irrigation of root end cavity with MTAD followed by subsequent retrofilling with MTA and biodentine: an in vitro study. J Consev Dent. 2015;18(2):132-5.

26. Mandava P, Bolla N, Thumu J, Vemur S, Chukka S. Microleakage evaluation around retrograde filling materials prepared using conventional and ultrasonic techniques. J Clin Diagn Res. 2015;9(2):43-6.

27. Rirattanapong $P$, Senawongse $P$, Harnirattisal C, Wunsiw W. Effect of smear layers created by different burs on durability of self-etching adhesive bond to dentin of primary teeth. J Clin Pediatr Dent. 2015;39(3):224-30.

28. Trivedi P, Dube M, Pandya M, Sonigra H, Vachhani K, Attur K. Effect of different burs on the topography of smear layer formation on the dentinal surface: a scanning Electron microscope study. J Contemp Dent Pr. 2014; 15(2):161-4

29. Bhagwat S, Heredia A, Mandke L. The smear layer revisited. Indian J Med Res Pharm Sci. 2016;3(1):54-65.

\section{Publisher's Note}

Springer Nature remains neutral with regard to jurisdictional claims in published maps and institutional affiliations.

Ready to submit your research? Choose BMC and benefit from:

- fast, convenient online submission

- thorough peer review by experienced researchers in your field

- rapid publication on acceptance

- support for research data, including large and complex data types

- gold Open Access which fosters wider collaboration and increased citations

- maximum visibility for your research: over $100 \mathrm{M}$ website views per year

At $\mathrm{BMC}$, research is always in progress.

Learn more biomedcentral.com/submissions 